\title{
Nutrition Levels, Food Consumption patterns and Health Status of Pre-school Children in Primary Schools in Owerri Municipal, Imo State, Nigeria
}

\author{
C. Asinobi, B. Ndimantang and N. Duru \\ School of Food Science and Technology, College of Agriculture and Veterinary Medicine \\ Imo State University, Owerri
}

\begin{abstract}
To assess the nutrition levels, health status as well as the food consumption pattern of pre-school children in some private and government schools in Owerri Municipal council, Imo State, Nigeria. Anthropometric measurements of 490 pre-school children aged $2-5$ years were obtained and assessed by National Center of Health Statistics (NCHS) reference population and according to WHO (1983) guidelines. Information on health status as well as food consumption pattern was obtained by structured questionnaires. The mean $z$ score anthropometric indices were above 2SD, cut off for determining those at risk. The percentages of nature of malnutrition were almost similar to $2.5 \%$; accepted value for prevalence of malnutrition in the countries of the world. Percentage of pre-school children consuming the different food groups at least once a week were highest in meat, milk followed by bread and cereals groups. Health status and sanitary facilities were adequate. Measurements of health status as well as food choice and consumption pattern give some initial indication of the probability of the household food insecurity and poverty alleviation factors in the community. Effort should be aimed particularly at ensuring diet quality of pre-school children in conjunction with healthy environiment.
\end{abstract}

\section{INTRODUCTION}

Pre-school children nutrition levels have been a major concern in nutrition studies because of their vulnerability to ill health. Studies have indicated that malnutrition, a public health problem is most prevalent in pre-school children (Morale et al 1991; Mazumder et al 1996). More than 175 million of children that are under five worldwide are presently believed to be under nourished according to weight-for-age criterion (Encyclopedia of Food Science, Food Technology and Nutrition, 1993). The United Nations recently estimated that some 150 million children are under-weight, about 20 million low birth weight infants are born each year, and some 40 million children are afflicted with vitamins deficiency (UN/ACC/SCN, 1991). Early malnutrition, which stunts growth, has been repeatedly reported to contribute to poor intellectual and physical development of children (Simondon, 1998) and consequently stifles development.

Food consumption of children has been reported to be deficient of protein foods. Kumar (1979) found that the consumption of meat and eggs of pre-school children was low and milk consumption decreased as the child grew older. Nnanyelugo (1982) reported that children are mainly fed on starchy roots and tubers leading to chronic malnutrition with low body weight and height for their age. When a child consumes a wide variety of healthful foods in adequate amounts, the potential for health and proper growth is excellent. Pre-school children are particularly at risk of malnutrition and health. Poor health status suppresses growth, reduces voluntary food intake and increases nutrient needs while poor 
nutritional status lowers immune competence and therefore increases susceptibility to infection (Latham, 1995). Malnourishment of children of under-five is inconsistent with building the long-term future generation of a country. This study determines the nutrition levels, food consumption pattern as well as the health status with the view of improving the nutritional status of pre-school children.

\section{MATERIALS AND METHOD}

Site and Sample Selection: This study was carried out in two government (Alvan Ikoku College of Education and Imo State University Staff Nursery/Kindergarten schools) and two private (Goshen and Start-right Nursery and Kindergarten) schools all located in Owerri Municipal Council Imo State, Nigeria. The sample population involved male and female pre-school children aged $2-5$ years. All the pre-school children in each school were selected for the study. A total sample size of 490 pre-school children was obtained.

Data Collection and Processing: Anthropometric measurements, namely, weight and height of the 490 pre-school children were taken by direct measurement following standard procedures established by WHO (1976). Weight and height data were converted into anthropometric indices (nutritional indices) using international reference population (de Onis and Habicht, 1996) that expresses values in form of Z-Scores. Standard deviation (S.D. Score; Z-score) of nutritional index for an individual was calculated by age class, according to age classification of WHO (1976), sex and overall sample with the following formula, and percentages of the nutritional levels of pre-school children obtained. Preschool children with incomplete data for any anthropometric indices were not included.

\section{S. D. Score - Actual child's measure - median reference population Or \\ Z-score \\ Standard deviation value of reference population}

The child's age was obtained from school records. Data on food consumption pattern, health status and socio-economic factors were collected through the use of structured questionnaires distributed to the mothers of pre-school children. Information on the food consumption patterns of the pre-school children was determined through a food frequency list method. At household level, the parents of each child in the schools were asked to recall the number of times daily and weekly as well as the number of servings each food item was consumed by each pre-school child.

The food item consumed and the percentage of pre-school children consuming each food item was calculated. The pre-school children were grouped according to the sub-groups of each of the factors examined and percentages of pre-school children in various sub-groups of the factors were calculated.

Journal of the Faculty of Agriculture and Veterinary Medicine, Imo State University, Owerri www.imsu-jafs.com 
Statistical Analysis: Student T-test was carried out to determine the levels of significance of the difference in mean weight for age, height for age and weight for height indices between sexes and age groups.

\section{RESULTS AND DISCUSSION}

Anthropometric Indices: The anthropometric Z-score of the pre-school children differ significantly $(\mathrm{P}<0.05)$ between the age groups (Table 1$)$. The $Z$-scores were lower in age group $48-<60$ month for weight for age, height for age and weight for height indices than in $24-<48$ months (Table 1). Between the ages of $48-<60$ months pre-school children have been introduced completely too family food. Adequate consideration of food choice of the pre-school children could be lacking. In most cases, the amount and quality of food consumed by the pre-school at this stage could be inadequate (Nnanyelugo, 1982).

Similarly, the Z-scores of the pre-school children were higher in males than in females for only weight for age and weight for height indices but differ significantly only in weight for height index $(\mathrm{P}<0.05)$. This observation did not agree with the findings of UNICEF/WHO (1985) who reported that from birth up to 6 years of age, girls have slightly more body fat than boys. However, the potential higher muscle mass in males than in females could have contributed to the higher weight for age and weight for height indices found in males. The higher but significant height for age index in females has been observed by Ahn and Shariff (1995) who reported that the rate of growth in height of females increases at a greater rate than in males after the control in standard height over a period of 46 months. Table 1 shows that the anthropometric Z-scores of the pre-school children were above - 2SD reference populations, the convectional cut-off point for Africa (WHO 1983). The observation concurs with the report of Tylleskar and Tylleskar (1988).

Prevalence of Nutrition Level of Pre-school Children: Figure 1 shows that the percentage of pre-school children under nourished, and stunted were higher in age group 48 $-<60$ months, but lower for wasting than in the age group $24-<48$ months. This suggests that adverse health effects accumulate with age during the first few years of childhood (Pelletier 1995, UN/HCC/SCN (1993). Older children are exposed to relatively poorer environment than younger children. In addition, studies of the rate of increase in length have revealed that stunting process starts in first year of life up to second year of life but becomes more prominent at the latter age (WHO, 1987). The observation that wasting was higher in age group $24-<48$ months than $48-<60$ months could be attributed to dietary deficiencies and diarrhea disease during weaning practices.

The percentages of pre-school children under-nourished, stunted and wasted were higher in females than in males. In most households, the head of the household and male children are given more preference during food sharing, because males are seen to succeed their fathers after death (Martorell et al 1984). Such practices could endanger the nutritional status of other members of the household especially in households where the economic situation is 
poor. However, the percentages of under nutrition and wasting among the pre-school children were similar to the acceptable level of malnutrition $(2.5 \%)$ in the countries of the world (WHO, 1983) while the percentage of stunting among the pre-school children was lower than the acceptable value. More so, the prevalence of malnutrition, was lower than that reported in Nigeria report (UN/ACC/SCN, 1993).

Table 1: Mean anthropometric Z-scores of pre-school children by age class and Gender

\begin{tabular}{lllllllllll}
\hline & \multicolumn{3}{l}{ Weight for age } & \multicolumn{3}{l}{ Height for age } & \multicolumn{3}{c}{ Weight for Height } \\
Age class (mth) & $\mathbf{n}$ & \multicolumn{2}{l}{ Z-score SD } & $\mathbf{n}$ & Z-score SD & $\mathbf{n}$ & Z-score SD \\
$24-<48$ & 132 & 0.57 & 1.04 & 132 & 0.54 & 1.16 & 265 & 0.32 & 0.89 \\
$48-<60$ & 237 & 0.09 & 1.10 & 233 & 0.19 & 1.04 & 118 & 0.17 & 1.02 \\
Gender & & & & & & & & & \\
Male & 184 & 0.21 & 1.01 & 183 & 0.18 & 0.99 & 201 & 0.24 & 0.82 \\
Female & 185 & 0.12 & 1.11 & 182 & 0.49 & 1.19 & 202 & 0.08 & 0.98 \\
Overall & 369 & 0.17 & 1.06 & 365 & 0.33 & 1.12 & 403 & 0.15 & 0.90 \\
\hline
\end{tabular}

Note: Pre-school children with incomplete anthropometric indices were not included
a) $\quad \mathrm{P}<0.05 ; \quad \mathrm{t}$-ratio -2.285 for age class, $\quad \mathrm{P}<0.05$, t-ratio- 1.37 for gender
b) $\quad \mathrm{P}<0.05 ; \quad \mathrm{t}$-ratio -3.08 for age class, $\quad \mathrm{P}<0.05$, $\mathrm{t}$-ratio $=4.60$ for gender
c) $\quad \mathrm{P}<0.05 ; \quad \mathrm{t}$-ratio $=4.20$ for age class, $\quad \mathrm{P}<0.05$, $\mathrm{t}$-ratio -4.98 for gender

Food Choice and Consumption: Table 2 shows that the highest percentage of the preschool children consumed more of meat than other food group. Milk, fruits and vegetables, and bread and cereals followed this. The least consumed food item was fats and oils. Similar consumption pattern has been reported in Ghana (Armar-Klemesn, 1995) where fish was eaten by more pre-school children at a lower per capita consumption, while the proportion of children eating dried and fresh vegetables were higher and more consistent all year round. The number of serving per day was above the recommended daily servings (Krause and Mahan, 1984) except for fruits and vegetables, and butter, fats and oils. Another possible explanation could be that the food groups were substituted to a certain extent with energy dense foods.

Health Status: The percentages of pre-school children who did not suffer from diarrhea, fever and cough were higher than those who suffered from the diseases (Table 3). The number of times the pre-school children suffered from the diseases in every two weeks were less than twice. More so, the percentage of pre-school children immunized was much higher than those that were not immunized. The low distribution and frequency of diseases observed in the pre-school children could be attributed to high level of immunization practice. Immunization is a means of preventing communicable diseases in children (UNICEF/WHO, 1985) and thus a safeguard for better nutrition and health. 
Table 2: Percentage of pre-school children consuming the different food groups at least once a week

\begin{tabular}{lllc}
\hline Food groups & $\mathbf{n}$ & $\frac{\text { \% }}{4}$ & $\frac{\text { Mean daily no. of servings }}{2.41}$ \\
\hline Milk & 198 & 40.41 & 2.11 \\
*Meat \& Fish & 207 & 42.24 & 2.31 \\
Fruit \& Vegetable & 207 & 42.24 & 1.97 \\
Bread and Cereal & 215 & 43.88 & 4.20 \\
Butter, fat, oil & 124 & 25.31 & 1.78 \\
\hline
\end{tabular}

$\mathrm{n}=490$

* Meat $=$ Meat and Fish group.

Table 3: Percentage and mean values of pre-school children by health factors

\begin{tabular}{|c|c|c|c|}
\hline$\frac{\text { Morbidity and }}{\text { Mortality factor }}$ & $\underline{\mathbf{n}}$ & $\%$ & $\begin{array}{l}\text { Mean no. of times } \\
\text { per two weeks }\end{array}$ \\
\hline \multicolumn{4}{|l|}{ *Diarrhea } \\
\hline Yes & 99 & 20.20 & 1.2 \\
\hline No & 391 & 79.79 & \\
\hline \multicolumn{4}{|l|}{ *Fever } \\
\hline Yes & 165 & 33.67 & 1.3 \\
\hline No & 325 & 66.32 & \\
\hline \multicolumn{4}{|l|}{${ }^{*}$ Cough } \\
\hline Yes & 196 & 40.00 & 1.1 \\
\hline No & 294 & 60.00 & \\
\hline \multicolumn{4}{|l|}{ Immunization } \\
\hline Yes & 365 & 74.48 & \\
\hline No & 125 & 25.51 & \\
\hline \multicolumn{4}{|l|}{ Number of children } \\
\hline \multicolumn{4}{|l|}{ From $2-5$ years } \\
\hline Alive & 383 & 78.16 & \\
\hline Dead & 107 & 21.83 & \\
\hline \multicolumn{4}{|l|}{ Sanitary facility } \\
\hline \multicolumn{4}{|l|}{ Indoor Kitchen } \\
\hline Yes & 386 & 78.77 & \\
\hline No & 104 & 21.22 & \\
\hline \multicolumn{4}{|l|}{ Indoor toilets } \\
\hline Yes & 381 & 77.75 & \\
\hline No & 109 & 22.24 & \\
\hline \multicolumn{4}{|l|}{ Source of water } \\
\hline Tap & 385 & 78.57 & \\
\hline Borehole & 93 & 18.97 & \\
\hline Stream & 12 & 2.44 & \\
\hline
\end{tabular}

*Number of pre-school children suffering from diarrhea fever and cough in the previous two weeks 
Furthermore, Table 3 shows that the percentage of pre-school children alive was higher than those dead. The observation could be as a result of good health-care practices among the households of the pre-school children. The percentages of pre-school children in households that have indoor kitchens, indoor toilets and access to tap water were higher than the others that had none. Gopaldas et al (1983) reported that poor sanitary conditions, specifically. source of water supply and toilet, adversely affect nutrition and health of children below four years of age. Similarly, Horwitz (1987) has reported a rapid decline in infant mortality due to decrease of potable water supply and sewage in urban areas. Water supply as well as basic sanitary facilities in the households of the children could have helped reduced childhood morbidity and mortality, thus enhancing the health status of the pre-school children.

The study shows that the nutrition and health status as well as food consumption pattern of pre-school children in some yrivate and government schools in Owerri Municipal is encouraging. However, efforts to maintain nutrition and health status should be focused through improved programmes for food security aimed particularly at ensuring diet quality in conjunction with promotiag appropriate healthy environment.

\section{REFERENCES}

Ahn, N. and Shariff, A., (1995). Determinants of child height in Uganda: A consideration of the selection, bias caused by child mortality. Food and Nutrition Bulletin, 16 (1).

Armar-Klemesn, Bikimaru, I., Kennedy, D. O., Harrison, E., Kido, Y and Takyi, E.E. K. (1995). Food and Nutrition Bulletin, 16(1):27-33.

De Onis, M. and Habicht, J. P. (1996). Anthropometric reference data for international use: Recommendations from World Health Drganisation Expert Committee. American Journal of Clinical Nutrition, 64: $650-6 \leqslant 8$.

Encyclopedia of Food Science, Food Technology and Nutrition (1993). Edited by Macrae, R. Robinson, R. K. Sadler, M. J., London Harcourt Brace Jovanovich, Academic Press Limited 5: 328 - 3307.

FAO (1990). Conducting small scale nutrition surveys: A field manual, nutrition planning, assessment and evaluation service food policy and nutrition division No. 5 .

Gopaldas, T., Patel, and Bakshi, M. (1988). Factcrs associated with nutritional status of infants and toddlers. Food and Nutrition Bulletin, 10 (4): $29-34$.

Horwitz, A. (1987). Comparative public health: Costa Rica, Cuba and Chile Food and Nutrition Bulletin, 9 (3): $19-29$. 
Krause, M. V. and Mahan, L. K. (1984). Food, Nutrition and Diet therapy. A textbook of Nutritional care. West Washington Square, Philadelphia pp. $192-214$.

Kumar (1979) .Impact of subsidized rice on food consumption and nutrition in Kerala Research report No. 5. Washington D. C. International Food Policy Research Institute.

Latham, M. C. (1995). Nutrition and Infection in National Development, Science 88: May 9 , pp $561-565$.

Martorell, R., Leslie, S. and Naquer, M.M.H. (1984). Characteristics and Determinants of child nutritional status in Nepal. American Journal of Clinical Nutrition, 39: $74-86$.

Mazumder, R. N, Kasir, I, Rahman, M. M., Khatun, M., Mahalanabis, D. (1996). Absorption of macronutrients from a calorie-dense diet in malnourished children during acute Shigellosis. J. Pediats. Gestroenterol Nutr., 23 (1) $24-8$.

Morale, E., Craig, L. D., Maclean, W. C., (1991). Dietary Management of Malnourished children with a new enteral feeding Diet Association, 91(10) 1233-8.

Nigeria Nutrition Situation Report (1993): Edited UN/ACC/SCN country case study for the second report on the world Nutrition Situation by Agary, T. and Gillespiers. Prepared for the XV congress of the International Union of Nutritional Sciences.

Nnanyelugo, D. O. (1982). The incidence of latent protein-energy malnutrition among the under-fives. Nigerian Journal of Nutrition Science 3: $11-24$.

Pelletier, D. L. (1995). The effects of malnutrition on child mortality in developing countries. Bulletin of the WHO, 73(4).

Simondon, K. B. (1998). Pre-school stunting, age at menarche and adolescent height: a longitudinal study in rural Senegal. European Journal of Clinical Nutrition, 52: 412 418.

Tylleskar; K and Tylleskar, T. (1988). Cassava and child health among sakata: A nutritional study of an ethnic group in northern Bandundu Region in Zaire. Minor field study report No. 16. International Child Health Unit Department of Paediatrics, Uppcala, University, Sweden 71p.

UN/ACC/SCN(1991). Brief on policies to alleviate under consumption and Malnutrition in deprived areas. Geneva. 
UN/ACC/SCN (1993). Nigeria Report on the Nutrition situation. Country case study for the second report on the World Nutrition situation. Adelondu E., Jimiebi Agery and Staurt Gillespie (eds). Prepared for the XV congress of the International Union of Nutritional Sciences Sept.26-Oct.1

UNICEF/WHO (1985). Fourth Programme report 1983 - 1984. (WHO/CDD/85.13) Geneva: WHO.

WHO (1976). Methodology of Nutritional Surveillance. Geneva(WHO Technical Reports, 593)

WHO (1983). Measuring changes in Nutritional Status: Guidelines for assessing the Nutritional Impact of supplementary feeding programmes for vulnerable groups, Geneva.

WHO (1987).Global Nutritional Status. Anthropometrics indicators. Nutrition Unit, Division of Family Health, Geneva. pp. 932-941.

\section{Acknowledgement}

The authors acknowledge with gratitude the comments and suggestions of Prof. B.E.B. Nwoke, Deputy Vice-Chancellor, Imo State University in data collection and analysis. 

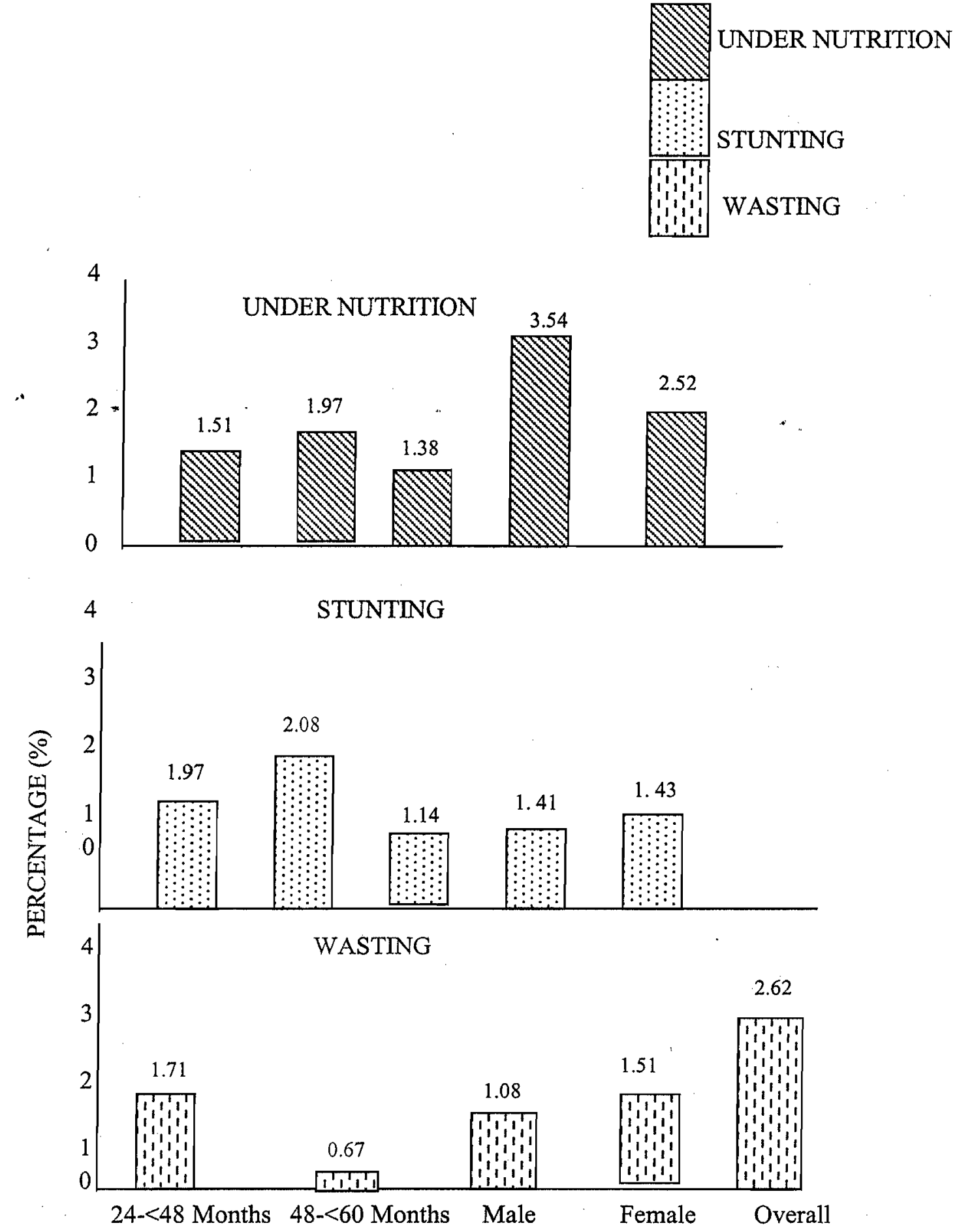

FIG. 1: Percentage of under nutrition, stunting and wasting among pre school children

Journal of the Faculty of Agriculture and Veterinary Medicine, Imo State University, Owerri www.imsu-jafs.com 